\title{
Fazer morrer, deixar morrer: das memórias que nos contam
}

- Making it die, letting it die: about the memories that are told to us

- Hacer morir, dejar morir: sobre los recuerdos que nos dicen

Silvia Brandão'

Resumo: $O$ artigo se estrutura como um experimento criado a partir de conceitos em geral inventados para pensar outros contextos, mas que operam como ferramentas articuláveis à compreensão da especificidade brasileira. Busco os efeitos que a violência de Estado e suas memórias exercem sobre os regimes de subjetivação do tempo presente, enquanto destaco crimes do Estado ditatorial e sua relação com as violações de direitos humanos operadas em democracia. Assim, a narrativa tem por eixo central os modos de produção das memórias que nos contam, que surgem articulados às políticas governamentais de fazer morrer, deixar morrer implementadas pela ditadura militar, ao mesmo tempo em que emergem conectados com acontecimentos da atualidade. Trata-se de um estudo em percurso, que prioriza a relação entre a Guerrilha do Araguaia, a Covid-19, as memórias fabricadas acerca desses eventos e os modos dominantes do desejar-fazer. O processo se constitui afetado por pensadores como Michel Foucault, Achille Mbembe e David Kopenawa.

Palavras-chave: Violência de Estado. Memória. Subjetividades. Ditadura. Covid-19.

1 Doutora em filosofia pela Unifesp. Pesquisadora do Núcleo de Filosofia e Política (Unifesp-CNPq). silmaribra@gmail.com 


\begin{abstract}
The article is structured as an experiment created from concepts generally invented to think about other contexts, but that operate as tools articulated to the understanding of Brazilian specificities. I look for the effects that state violence and its memories have on the subjectivation regimes of the present time, while I highlight the crimes of the dictatorial state and its relation with the human rights violations operated in the democracy. The narrative has as its central axis the production forms of the memories that are told to us, which appear interconnected with the governmental policies of making it die, letting it die implemented by the military dictatorship, at the same time that they emerge connected with current time events. This is an ongoing study, which prioritizes the similarity between the Araguaia Guerilla War, the Covid-19, the produced memories of these events and the dominant ways of wanting-doing. The process affected by thinkers like Michel Foucault, Achille Mbembe and David Kopenawa.
\end{abstract}

Keywords: State violence. Memory. Subjectivities. Dictatorship. Covid-19

Resumen: El artículo se estructura como un experimento criado a partir de conceptos en general inventados para pensar en otros contextos, pero que operan como herramientas articuladas a la comprensión de la especificidad brasileña. Busco los efectos que la violencia de Estado y sus memorias ejercen en los regímenes de subjetivación del tiempo presente, mientras destaco crímenes del Estado dictatorial y su relación con las violaciones de derechos humanos operadas en la democracia. La narrativa tiene por eje central los modos de producción de las memorias que nos relatan, que surgen vinculados a las políticas gubernamentales de hacer morir, dejar morir implementadas por la dictadura militar, al mismo tiempo que emergen conectados con acontecimientos de la actualidad. Se trata de un estudio en curso, que prioriza la similitud entre la Guerrilla del Araguaia, el Covid-19, las memorias fabricadas sobre estos hechos y los modos dominantes del dejar-hacer. El proceso se constituye afectado por pensadores como Michel Foucault, Achille Mbembe e David Kopenawa.

Palabras clave: Violencia de Estado. Memoria. Subjetividades. Dictadura. Covid-19.

\title{
1. A morte do Outro como dispositivo necropolítico
}

Eu me encontrei com Davi em 85 pela primeira vez e ele me perguntou, fui visitar ele lá na floresta ele me perguntou: é verdade que os bran- 


\begin{abstract}
cos são muitos? Aí eu fiquei pensando como que eu ia responder essa pergunta do meu amigo, porque eu sei que para os Yanomami muito é tudo que é mais do que sete, oito, dez. Muito. As coisas que pode se contar com os dedos da mão já são muito. Eu falei eu não posso enganar ele de que os humanos sejam só o número dos dedos das mãos, algumas coisas assim. Mas eu também não queria apavorar ele, então eu disse eu não posso deixar ele enganado sobre isso. Aí eu disse: olha, os brancos são tanto quanto as estrelas do céu, a areia das praias, dos igarapés, dos rios. Eles são tantos assim. Ele ficou muito assustado. Depois ele me perguntou: e o que eles comem? Aí eu disse: olha... eles comem de tudo. Eles comem árvores, eles comem pedra, eles comem rios, eles comem tudo, tudo. Essa floresta sua toda eles comem. Ele ficou mais apavorado ainda. E me perguntou: e onde eles cagam? Eu disse: eles cagam no mundo 2 .
\end{abstract}

Michel Foucault em Vigiar e Punir (1999) descreve a biopolítica como parte das estratégias de controle da população. Para o pensador, ela é uma prática de governo que não substitui o poder disciplinar, o qual surgiu no século 17 como tecnologia de adestramento em instituições como escolas, hospitais, prisões e fábricas, para produzir, por meio de sistemas de controle, vigilância, hierarquia e sanção normalizadora, corpos-dóceis, corpos-máquinas. Ao contrário, regula-nos em complementaridade com a soberania do direito e o adestramento individual dos corpos, caracterizando-se como uma prática que age hibridamente.

Um modo de governar que coloca a vida no centro das engrenagens: fazer viver, deixar morrer. Uma forma de governo que opera por meio de aparentes impessoalidades como as alocuções do "Bem" contra o "Mal", ao mesmo tempo em que se conecta a conhecimentos científicos que se compõem ilusoriamente imparciais. Discursos e práticas que pautam o cuidado para com a vida da população ou do homem espécie, enquanto se associam à implementação de tecnologias de contenção de riscos, que no Brasil associamos à violência que usualmente o aparelho de Estado direciona contra os corpos-indóceis como os insubmissos, os subalternizados, os coisificados. Modelo de governo que, em conjunto com o ordenamento jurídico, legitima práticas de chefes do Executivo, de deputados, juízes, economistas, delegados, jornalistas, policiais militares, Forças Armadas, maiorias, homens brancos etc.

Contudo, o fazer viver, deixar morrer de Foucault é ainda insuficiente para a compreensão dos modos brasileiros de desejar-fazer. No Brasil, embora criem-se políticas focadas no cuidado para com a vida da população como são, por exemplo, o bolsa família, as cotas universitárias e as medidas de reparação destinadas aos familiares das vítimas e aos sobreviventes da repressão política ditatorial. Ações que podem ser compreendidas - ao mesmo tempo

2 A transcrição do extrato da fala de Ailton Krenak é de minha responsabilidade. Cf. Selvagem ciclo de estudos sobre a vida. Ailton Krenak, chefe Seattle e Davi Kopenawa. Disponível em: https://www.youtube.com/watch?v=8bMuUE4KD3w. Acesso em: 31 out. 2020. 
- como decorrentes de lutas minoritárias e parte de um programa de governo cujos efeitos passam pela minimização da desigualdade social, pela dissolução de implicações do racismo e pela elaboração do traumático. Ocorre que o mesmo aparelho de Estado opera também um conjunto de políticas cujo objetivo não é cuidar da vida de corpos fabricados danificados, mas fazer morrer, deixar morrer múltiplas categorias de corpos marcados como matáveis.

A partir de Mbembe pode-se dizer que no Brasil os discursos e práticas de morte fazem parte de uma estratégia necropolítica, que se caracteriza por um modo de operar que subjuga corpos periféricos, negros, selvagens, rebeldes e minoritários ao poder da morte. Fazer morrer pela mão das Forças Armadas e suas polícias militares, deixar morrer pelos ataques de mercenários do capitalismo cujos correlatos são os desdobramentos da miséria social, do racismo, do genocídio e etnocídio estruturais ${ }^{3}$.

São práticas fundadas a partir do colonialismo europeu, macho, branco e sua invenção do Outro sem alma, lei ou rei. Trata-se da criação racial moderna, que no processo de invenção e alastramento do capitalismo concebe a ideia da superioridade do homem ocidental, ao mesmo tempo em que transforma tudo que lhe é diferente em seu oposto, o Outro matável (MBEMBE, 2018b)

Trata-se da desdobra do racismo descrito por Foucault como uma forma de eliminação de tudo que afeta a vida da população (2005). Assim, reafirmando a necropolítica que nos constitui (MBEMBE, 2018a), no território brasileiro o racismo não atua do mesmo modo que no contexto europeu. A cotidianidade e a forma como se estruturam e se operam as práticas de morte direcionadas aos cidadãos fabricados como o Outro do homem branco e majoritário, autoriza-nos a dizer que no Brasil não é a vida, mas a morte que ocupa o centro das engrenagens. Mesmo quando ocorrem atividades associadas a discursos e práticas de cuidado para com a vida, em geral são as políticas de morte que constituem o núcleo imprescindível e duro das ações governamentais.

No processo, os efeitos dessas práticas agem nos regimes de subjetivação fazendo-nos operar pela lógica nós versus os Outros. Nós que somos indiferentes à morte dos Outros. Nós que deixamos os Outros expostos a prematuras paradas de respiração. Nós que decretamos guerra contra os Outros. Nós que matamos os Outros.

É preciso dizer ainda que, embora constituídas ao longo da história, no Brasil as políticas de morte da atualidade não são somente vestígios do passado

3 O conceito de genocídio surge em âmbito legal a partir do Tribunal de Nuremberg (1946). Já o conceito de etnocídio emerge da realidade indígena da América do Sul. Apesar das dissimetrias, eles se referem a dois modos de fazer morrer, deixar morrer. Se o genocídio mata fisicamente a "raça má", o etnocídio visa destruir a "cultura má". Dois tipos de mortes, de massacres, que no Brasil atingem múltiplos corpos e culturas, são denunciados e não cessam. Sobre os conceitos cf. CLASTRES, 2004, p. 55-63. 
colonial que chegam ao presente. Nem mesmo apenas restos esquecidos pelo processo de transição da ditadura militar para a democracia. Também não são meros desvios, aos quais o governo recorre em casos emergenciais, mas políticas de Estado do tempo presente. Como pensa Guattari, as teorias e os métodos que operam no contemporâneo não pertencem a um tempo anterior. Ao contrário, são sobrecodificadas "por nossas referências no presente" (2012, p. 114).

\section{O (in)comum da morte programada e suas memórias lacunares}

Na ausência de camas hospitalares, máquinas respiratórias, testes em quantidade, máscaras, desinfetantes à base de álcool e de outros dispositivos de quarentena para quem já foi atingido, infelizmente prevemos que muitos não passarão pelo buraco da agulha. (MBEMBE, 2020, s/n).

Inspirar-expirar... Inspirar-expirar... Inspirar-expirar... Inspirar-expirar... A respiração pode ser compreendida como uma ação natural e involuntária assim como uma movimentação programada, apreendida, esticada, encurtada ou intencionalmente interrompida. Contudo, apesar de suas variáveis, ela se apresenta primeiramente como um ato biologicamente vital. Se deixamos de respirar, sufocamos, morremos.

Desse modo, para além do tecnicamente apreendido, por exemplo, em práticas de yoga, a respiração é "algo que nos é comum e que, por definição, escapa a qualquer cálculo. Falamos, assim, de um direito universal de respiração" (MBEMBE, 2020, s/n). Mas o que ocorre quando esse direito é suspenso? Morremos todos?

Dizem que as vítimas da Covid-19 morrem com os pulmões cheios de água, afogadas em seus próprios corpos. As tomografias dessas mortes se assemelham a dos mortos por afogamento (BONALDI apud OLIVEIRA, 2020, $\mathrm{s} / \mathrm{n}$ ). Porém antes do novo vírus, partes da humanidade não cessavam de morrer asfixiadas. Como diz Mbembe, em sua longa duração o "capitalismo, confinou segmentos inteiros de populações e raças inteiras a uma respiração difícil, ofegante, a uma vida pesada" (2020, s/n).

No Brasil, em 4 dezembro de 2019, na cidade de São Paulo, num lugar de difícil respiração, durante uma ação da Polícia Militar num baile funk no bairro de Paraisópolis, na Zona Sul, nove jovens negros, segundo autoridades, morreram pisoteados. Antes da conclusão da necropsia, o Instituto Médico Legal (IML) apontou que ao menos dois deles vieram a óbito devido a "'asfixia mecânica por sufocação indireta', ou seja, acabaram sufocados" (DANTAS; CA- 
ETANO, 2019, s/n $)^{4}$.

$\mathrm{Na}$ época, familiares das vítimas relataram que identificaram seus entes queridos pelo rosto, mas o IML os proibiu de verificar o restante de seus corpos. Posteriormente, investigação feita pela Corregedoria da Polícia Militar de São Paulo concluiu que os 31 policiais militares participantes da ação não haviam cometido irregularidades (STABILE, 2020, s/n). Vale lembrar que a versão da ditadura para o assassinato do jornalista Vladimir Herzog foi "enforcamento por asfixia mecânica".

Herzog foi assassinado pelo Estado brasileiro em 1975, mas somente em 2013, no contexto dos trabalhos da Comissão Nacional da Verdade, é que seu atestado de óbito foi retificado para "morte por lesões e maus-tratos sofridos durante o interrogatório nas dependências do segundo Exército DOI-Codi" (Destacamento de Operações e Informações-Centro de Operações e Defesa Interna). No entanto, o que ocorreu com o jornalista aconteceu também com milhares de vítimas que tiveram sua respiração interrompida pelo aparelho de Estado ditatorial, que por sua vez tornou igualmente difícil, ofegante e pesada a respiração de incontáveis sobreviventes.

Num mergulho pelas memórias que circulam a ditadura, pode-se afirmar que em decorrência das lutas de familiares de vítimas, sobreviventes e ativistas de direitos humanos, sabe-se sobre parte do ocorrido com a diversidade de corpos que tiveram sua respiração interrompida pelo aparelho ditatorial como foram os corpos dos militantes políticos assassinatos e desaparecidos, os mortos pelo Esquadrão da Morte, as vítimas da violência de gênero, LGBTs, camponesas e indígenas (COMISSÃO Nacional da Verdade, 2010).

Sabe-se ainda que o número de afetados é incerto. A historiadora Janaina Teles, em sua tese de doutoramento adverte que em seus primeiros meses a ditadura sequestrou, prendeu e provavelmente torturou cerca de 50 mil pessoas (2011, p. 83). A contagem pode ser maior, já que em 2019 o Intercept divulgou um ofício de 1964 onde consta que "foram efetuadas cerca de 20 mil prisões nos primeiros dias da revolução". A matéria fala também sobre um Informe de abril de 1964 onde há indicações de que o Exército armou cidadãos para fazer "ações de limpeza" nas ruas (prender pessoas), tendo desaparecido com presos (CAVASSA; CESAR, 2019, s/n).

Até 2009 a Comissão de Familiares de Mortos e Desaparecidos Políticos catalogou 436 militantes mortos e desaparecidos (DOSSIÊ Ditadura, 2009). E segundo o site da Comissão de Anistia, responsável pela efetivação de medidas de reparação para perseguidos políticos atingidos por danos trabalhistas, até 2017 foram protocolados mais de 75 mil pedidos de anistia política.

4 Asfixia: interrupção da respiração. Asfixia mecânica: compressão das vias aéreas provocada por elemento externo. 
A Comissão Nacional da Verdade indica um número de vítimas fatais próximo de 10 mil mortos ${ }^{5}$. Se a esse total acrescentássemos os pedidos de anistia protocolados até 2017, os dados saltariam para 85 mil casos. Se inspirados ainda na Convenção Internacional para a Proteção de Todas as Pessoas Contra o Desaparecimento Forçado (ONU-2006), estendêssemos a categoria vítima para todo o indivíduo que devido à ação promovida pelo Estado brasileiro, sofreu danos em decorrência direta de perseguição, sequestro, tortura, assassinato ou desaparecimento forçado de um ente querido, esse total aumentaria em progressão inumerável ${ }^{6}$.

Entretanto, apesar de suas inumeráveis vítimas a ditadura não inventou a brutalidade governamental, apenas modernizou-a. Dentre outras formas, essa atualização ocorreu através da introdução de teorias e práticas como as ações que circulam em torno do conceito de inimigo interno, que transformou cidadãos comunistas em terroristas ameaçadores da pátria e da família brasileira. Pode-se dizer que o conceito funcionou como peça justificadora dos massacres travestidos de guerra em defesa da segurança nacional ${ }^{7}$.

$\mathrm{Na}$ época dos fatos, militantes que vivenciavam o estado vítima escreveram uma Carta Denúncia, em que apresentaram técnicas de fazer morrer, deixar morrer utilizadas pela ditadura. Indicando ainda nomes de desaparecidos políticos e de agentes estatais operadores de máquinas governamentais de triturar e desaparecer com corpos ${ }^{8}$. Dentre as técnicas descritas estão o "afogamento" e o "sufocamento".

Afogamento": é um método de tortura cuja aplicação varia de um órgão repressivo para outro. Uma das formas mais comuns consiste em derramar-se água, ou uma mistura de água com querosene, ou amoníaco ou outro líquido qualquer pelo nariz da vítima já pendurada pela cabeça para baixo (como, por exemplo, no "pau-de-arara"). Outra forma consiste em vedar as narinas e introduzir uma

5 Desse total há ao menos 8.350 vítimas indígenas, 1.196 camponesas e mais de 400 mortos e desaparecidos políticos. Cf. COMISSÃO Nacional da Verdade (2014).

6 Artigo 24 da Convenção: "1. Para os fins da presente Convenção, o termo 'vítima' se refere à pessoa desaparecida e a todo indivíduo que tiver sofrido dano como resultado direto de um desaparecimento forçado". A Convenção foi firmada pelo Estado brasileiro em 2007 e regulamentada pelo Decreto 8.767/16. Disponível em: http://www. planalto.gov.br/ccivil_03/_ato2015-2018/2016/decreto/D8767.htm. Acesso em: 20 jan. 2019.

7 Se nas guerras do ocidente autoproclamado civilizado, em geral a ideia de guerra sugere certa equivalência entre os modos de operar dos dois lados em conflito, o conceito de massacre pressupõe o extermínio de corpos impossibilitados de defesa. Sobre os massacres de opositores políticos ocorridos durante a ditadura cf. DOSSIÊ Ditadura (2009); COMISSÃO Nacional da Verdade (2014).

8 Trata-se da carta de 1975 que ficou conhecida como Bagulhão. Ela foi produzida por presos políticos recolhidos na Justiça Militar de São Paulo. Tendo se notabilizado por ser a primeira denúncia coletiva escrita em primeira pessoa. Direcionada à Ordem dos Advogados do Brasil, o mote que deu origem à Carta foi a declaração do Presidente da $\mathrm{OAB}$, à época Caio Mário da Silva Pereira, que afirmou ao jornal Folha de S. Paulo não possuir fatos objetivos que possibilitassem a denúncia judicial de arbitrariedades policiais (BAGULHÃO, 2014, p. 12). 
mangueira na boca, por onde é despejada a água. Outras formas, ainda, são: mergulhar a cabeça do preso em um tanque, tambor ou balde de água, forçando-lhe a nuca para baixo; "pescaria", quando é amarrada uma longa corda por sob os braços do preso e este é lançado em um poço ou mesmo em rios ou lagoas, afrouxando-se e puxando-se a corda de tempo em tempo (BAGULHÃO, 2014, p. 17). [...]

"Sufocamento": consiste em tapar a boca e o nariz do preso com pedaços de pano, algodão etc., produzindo intensa sensação de asfixia e impedindo-o de gritar. Aplicado intermitentemente, o sufocamento provoca tonturas e desmaios do torturado (BAGULHÃO, 2014, p. 18).

Em democracia o aparelho de Estado modernizará as invenções do regime ditatorial. Se por um lado, a Polícia Militar inventada em 1969 não acabou e a tortura, o assassinato e o desaparecimento forçado seguem como práticas de Estado, por outro, no contemporâneo o conceito de inimigo interno passou a abranger também outras categorias de cidadãos "indesejáveis". Dentre tantos fatos, são casos exemplares as vítimas de Paraisópolis assim como os corpos negros, indígenas, encarcerados e sem teto, que além de serem usualmente foco da violência estatal e dos desdobramentos da desigualdade social e do racismo, no tempo presente constituem-se as principais vítimas da Covid-199.

Em outros termos, se conectarmos técnicas de tortura utilizadas pela ditadura como o "afogamento" e o "sufocamento" com a forma como morreram os jovens de Paraisópolis e a maneira como a Covid-19 suspende a respiração de suas principais vítimas, notaremos similaridades entre essas diferentes categorias de cidadãos afetados. Sob algum aspecto, todos foram primeiramente produzidos como corpos matáveis. Por isso, os sobreviventes, e ainda que de modo diverso, também familiares de vítimas, trazem em seus corpos e subjetividades as marcas e os rastros do que vivenciaram ao passarem por uma espécie de asfixia provocada pelo poder estatal de morte ${ }^{10}$.

$\mathrm{Na}$ atualidade, a declaração "quem é de direita toma cloroquina, quem é de esquerda Tubaína" evidencia a vinculação ${ }^{11}$. Como circulou nas redes sociais, o termo Tubaína associa-se a um refrigerante de São Paulo, atribuído

9 Sobre as categorias de vítimas mais atingidas pela Covid-19 no Brasil, cf. Boletins CAAF/Unifesp. Boletim CAAF/ Unifesp de enfrentamento da Covid-19. MORTOS E MORTES DA COVID-19: SABERES, INSTITUIÇÕES E REGULAÇÕES.

10 É interessante lembrar ainda, que em 19 de novembro de 2020, na cidade de Porto Alegre, através das mãos de seguranças que atuavam na rede de supermercados Carrefour, tivemos o espancamento seguido de morte de João Alberto Silveira Freitas. Se por um lado, o assassinato de João Alberto não decorreu da ação de agentes estatais, por outro, trata-se de um dos efeitos do racismo que nos constitui e faz com que parcelas da coletividade sejam agenciadas para compreenderem corpos negros como suspeitos iguais a culpados.

11 Em 19 de maio de 2020, dia em que o presidente fez essa declaração, o país registrava oficialmente mais de mil mortes e um número acumulado de 18 mil vítimas fatais da Covid-19. Em novembro de 2020 esse número ultrapassava 170 mil vítimas. Em janeiro de 2021, superava 200 mil mortes. 
ao consumo da população pobre. Pode ser também compreendido como alusão ao processo de intubação provocado pela Covid-19. Articula-se ainda aos "métodos e denominações da prática da tortura por afogamento usada nos presídios, delegacias e salas de tortura nos tempos de ditadura. Tanto contra presos políticos, como contra os presos da justiça comum e as vítimas do esquadrão da morte" (DIOGO, 2020, s/n).

Para Adriano Diogo, sobrevivente das máquinas de triturar corpos do período ditatorial e presidente da Comissão Estadual da Verdade de São Paulo, se o termo não consta em documentos, é preciso dizer que muitas coisas não foram registradas, talvez a expressão"nunca apareça. Como tantos outros fatos que foram sufocados durante mais de 30 anos, apesar de todos os esforços empreendidos até agora" (2020, s/n).

A fala de Adriano Diogo associa-se ainda ao acesso negado aos familiares das vítimas de Paraisópolis aos corpos de seus entes queridos, comprovando-nos que as tecnologias de fazer morrer, deixar morrer, mesmo quando aplicadas em diferentes contextos e por diferentes governos, são marcadas por ocultamentos que em geral incluem o apagamento das provas dos crimes de Estado da memória, das subjetividades e das responsabilidades.

São lacunas intencionalmente programadas que não apenas afetam familiares de vítimas e sobreviventes como provocam efeitos nas percepções e nos modos de agir das categorias de cidadãos não diretamente atingidos. São vazios de memória que agem em processos produtores de "indivíduos normalizados, articulados uns aos outros segundo sistemas hierárquicos, sistemas de valores, sistemas de submissão - não sistemas de submissão visíveis e explícitos (...). Não somente uma produção de uma [...]. - subjetividade dos indivíduos mas uma produção de subjetividade social" (GUATTARI; ROLNIK, 1996, p. 16).

No percurso, dentre outras coisas infiltram-se sentidos na memória coletiva acerca da violência governamental. O Estado só usa a violência contra os violentos. O Estado só usa a violência em defesa da sociedade. A ideia é criar uma população constituída para aceitar a violência institucionalizada como se ela fosse necessária ao combate do cidadão inimigo, o Outro, o diferente, 0 amedrontador, o negro, o selvagem, o matável.

São medos fabricados em desdobra: teme-se a crise econômica, o desemprego, o desencarceramento, as balas perdidas, os militantes radicais, a legalização do aborto e da maconha, as trans, as vadias, as putas e os imorais, os povos indígenas, os quilombolas, os moradores de rua, os pobres, o vírus. Usando as palavras de Deleuze e Guattari, essas produções são parte de uma grande segurança molar organizada, que "tem por correlato uma microgestão de pequenos medos, toda uma insegurança molecular permanente, a tal ponto que a fórmula dos ministérios do interior poderia ser: uma macropolíti- 
ca da sociedade para e por uma micropolítica da insegurança" (2012, p. 102). Com a Covid-19 o medo associa-se ainda ideia de combate ao vírus. A guerra é contra o vírus, mas o medo faz com que nos voltemos também contra quem o transmite. Aceitamos a morte do Outro, enquanto as vítimas se aglomeram na pilha de cadáveres histórica e contemporaneamente fabricados pelas (in) ações do aparelho de Estado.

O país se destaca pelo extermínio do Outro, do matável, do inimigo interno. Sendo conhecido pelo genocídio dos povos originários e da população negra. Ostenta também o título de terceira população carcerária do planeta sem que isso aparente estranheza. Sobressai-se ainda por matar defensores de direitos humanos e por tratar crimes de Estado como se não fossem crimes. No processo, as (in) comuns e programadas omissões de memória tornam-se peças produtoras de sujeitos adeptos das atuais políticas de morte.

No entanto, como algo sempre resta no revirar das temporalidades, das memórias e dos acontecimentos há rastros que emergem como singularidades reveladoras do modo como operam as tecnologias governamentais de morte e controle da memória e das subjetividades. Com relação à ditadura o massacre à Guerrilha do Araguaia constitui-se evento paradigmático.

\section{O massacre à Guerrilha do Araguaia: mortes, desapa- recimentos, memórias}

Os arquivos do DOPS (Departamento de Ordem Política e Social) foram abertos (...). Mas os arquivos quando foram abertos estavam limpos, porque, dez anos antes, o ex-diretor do DOPS, o Romeu Tuma, virou diretor da Polícia Federal para cuidar desses arquivos. Nós achamos alguma coisa nas entrelinhas, mas falta muito documento, inclusive os documentos sobre a guerrilha do Araguaia. As páginas estão numeradas e tem muita página faltando. Pelo arquivo do DOPS, a gente vê que qualquer papelzinho, qualquer memorando era registrado. Só abriram para nós as coisas de menor relevância. Valeu, porque, por exemplo, pessoas que a gente achava que tinham sido mortas em tiroteio, foram torturadas e as fotos estavam lá. Não tem crime perfeito. Os caras tiraram as páginas referentes ao Araguaia e esqueceram de tirar o índice, o que só mostra que existe e você não tem acesso (ALMEIDA in UCHIANAKA, 2009, s/n) 12 .

A Guerrilha do Araguaia surge a partir do experimento de uma máquina revolucionária e desejante, que buscou criar modos solidários de habitar-

12 Entrevista concedida pela ex-guerrilheira Crimeia de Almeida, cerca de um ano antes do Estado brasileiro ser condenado pela Corte Interamericana de Direitos Humanos pelo caso Araguaia. Note-se, antecipando-se a sentença da Corte, em abril de 2010 o Supremo Tribunal Federal revalidou a interpretação da lei de anistia de 1979 e os agentes ditatoriais permanecem impunes. Sobre o caso Araguaia cf. CORTE (2010). Sobre a revalidação da interpretação da lei de anistia cf. QUEIROZ (2019). 
mos o comum. Os guerrilheiros começaram a chegar ao sul do Pará em 1967. Em meados de 1974 quase todos haviam desaparecido. Seus corpos foram enterrados em locais até hoje ignorados ${ }^{13}$.

Os guerrilheiros foram exterminados pelo que se convencionou distribuir em três campanhas. Na primeira delas o Estado brasileiro já agia como se estivesse numa operação de caça. Houve destruição de depósitos de alimentos, montagem "de vigília em estradas, fazendas, castanhais, vilarejos e 'bocas de rio'; espalharam folhetins chamando os guerrilheiros de 'terroristas', 'assaltantes de banco' e 'maconheiros'[...]" (COMISSÃO Nacional da Verdade 2014, v. I, p. 688). Na segunda foram mobilizados cerca de cinco mil homens contra um número de guerrilheiros que não chegava a 80 corpos. Por fim, na terceira campanha a operação voltou-se para a aniquilação total, tendo sido presos e torturados também centenas de moradores acusados de constituírem redes de apoio da Guerrilha (COMISSÃO Nacional da Verdade, 2014, v. I) ${ }^{14}$.

A historiadora Janaina Teles (2011, p. 90), a partir de Giorgio Agamben (2004) e Hannah Arendt (1989), demonstra que para massacrar e ao mesmo tempo fazer desaparecer os rastros da aniquilação, o aparelho de Estado adotou técnicas similares às utilizadas em campos de concentração. No entanto, a partir de Mbembe imaginamos os campos do Araguaia também como atualizações de políticas de morte que em nosso território foram primeiramente destinadas aos povos indígenas e logo após aos negros escravizados, historicamente tratados como o Outro do humano.

Dito de outro modo, como ocorre desde a colonização com indígenas e negros, os guerrilheiros do Araguaia, ao serem compostos como inimigos internos foram também fabricados como se seus corpos fossem despossuídos de caráter especificamente humano. Relatos de moradores da região indicam que dentre outras ações guerrilheiros tiveram suas mãos e cabeças cortadas (COMISSÃO Nacional da Verdade, 2014, v. I, p. 712). "O corpo do guerrilheiro João Carlos Haas Sobrinho foi exposto à população de Porto Franco (MA), onde havia morado inicialmente. O corpo de Osvaldo Orlando da Costa foi pendurado em um helicóptero e exibido em toda a região" (TELES, 2011, p. 105).

Ao menos nesse aspecto, contrariando Foucault, quando diz que, no final dos séculos 18 e começo do 19, inicia-se a suspensão da "festa" punitiva da morte (1999), no século 20 o Estado brasileiro produz espetáculos mortíferos e públicos para uma população amedrontada e fragilizada. Pode-se di-

13 Até o momento apenas os restos mortais de dois desaparecidos foram identificados: Maria Lúcia Petit (1996) e Bergson Gurjão Farias (2009), ambos por ações dos familiares.

14 Foram torturados camponeses que nem sequer haviam aderido à Guerrilha. O povo indígena Aikewara foi mantido cativo na própria aldeia e torturado. Integrantes da etnia foram forçados ainda a atuarem como guias da ditadura. Cf. COMISSÃO Nacional da Verdade, 2014, v. I. 
zer que um dos objetivos dessas macabras cenas era exercer o controle das memórias e das subjetividades, fazer os moradores vivenciarem o que ocorre com quem ousa contrariar a ordem, fazê-los reter que ao final os corajosos guerrilheiros não passavam de cadáveres mutilados.

Contudo, o mesmo Estado cala-se diante dos familiares dos guerrilheiros desaparecidos, reservando-lhes o vazio da incerteza de uma morte sem corpo. Restando ainda para os não diretamente afetados uma percepção duvidosa sobre o que de fato ocorreu no Araguaia. Os corpos dos guerrilheiros estão mesmo desaparecidos? Eles estão de fato mortos? Não estão hoje vivos? Vivendo em lugares desconhecidos? Afinal esse massacre não seria exagero de comunistas ressentidos?

Somente em 1993 as Forças Armadas reconheceram a existência da Guerrilha, mas se recusam a abrir seus arquivos. Alegam que os documentos foram destruídos. Seguem também construindo narrativas em que "ora há insuficiência de informações, ora a pluralidade de relatos sobre um mesmo fato (COMISSÃO Nacional da Verdade, 2014 v. I, p. 680-681).

Em síntese, passadas décadas do massacre e depois de uma década da condenação da OEA, as Forças Armadas negam-se a contribuir com a investigação da verdade histórica, assim como atos de justiça permanecem bloqueados e os restos mortais das vítimas de desaparecimento forçados seguem não localizados. Em decorrência, familiares dos desaparecidos do Araguaia e familiares de outras vítimas de desaparecimento forçado fabricadas pela ditadura continuam constituídos por um luto irrealizado. A ausência do corpo impossibilita-os de simbolizarem a perda. No processo, embora gritem por justiça tornam-se também dominados por um passado que não conseguem representar e que não se desprega deles (FREUD, 1996).

$O$ fato é que os desaparecidos do Araguaia não podem dar seu testemunho e documentos oficiais seguem lacrados. A população da região, afetada pelo trauma e pelo medo, cala-se. Por isso, o que se escreve sobre o massacre são composições fundamentadas em ausências. Vazios que não se expressam pelo signo do vivido, mas pelo que lhe falta e ao mesmo tempo lhe excede como suplemento. Como afirma Vecchi:

O modo como se produziu o Araguaia permite definir uma sintaxe simbólica do massacre, (...) uma narrativa, que repete e se repete na diferença das performances - pense-se na cena da tortura ou de outros contextos repressivos do tempo - que agem sobre os corpos do inimigo $(2014$, p. 141).

Na cartografia que traçamos acerca da composição das memórias do massacre, é como se as víssemos atuando em diferentes planos e ao mesmo tempo em perspectiva cruzada. Assim, para além das lutas que circulam em 
torno dos mortos e desaparecidos do Araguaia, vemos as memórias do massacre nos revelarem estratégias governamentais produtoras de mortes físicas, ausências memorialísticas, históricas e judiciais que agem no tempo presente, ao mesmo tempo em que emergem táticas de resistência, e cujos efeitos não atravessam apenas subjetividades específicas.

Dito de outro modo, essas memórias não estão restritas ao instituído pelo confronto aparentemente circunscrito aos sujeitos sociais vítimas políticas versus militares descontrolados, já que operam para além dos contornos estabelecidos pela democracia do tipo vítima/culpado. Atuam também como singularidades resistentes e reveladoras das táticas governamentais de fazer morrer, deixar morrer, que de diferentes formas afetam toda a comunidade política e no percurso das temporalidades repetem-se atualizadas.

\section{Do massacre da Guerrilha ao genocídio da Covid-19: qual memória?}

Não somos ruins, só não somos brancos [...]. Os brancos não podem dizer que nós somos maus ou ferozes apenas porque queremos vingar nossos mortos! Não matamos ninguém por mercadorias, por terra ou por petróleo, como eles fazem! Brigamos por seres humanos. Guerreamos pela dor que sentimos por nossos parentes recém-falecidos (KOPENAWA; ALBERT, 2019, p. 278-445).

No Brasil, o aparecimento do novo vírus tornou-se "oportunidade" à intensificação do fazer morrer, deixar morrer, que a partir de 2019 o aparelho de Estado tem ativado com redobrada intensidade. Em meio à Covid-19 não apenas eleva-se a cifra de vítimas da violência estatal, como potencializa-se o alastramento do contágio ${ }^{15}$.

No processo, blefes e omissões fabricadas pelo representante do poder central como "É apenas uma gripezinha" ou "E daí?" operam como táticas de produção da morte ${ }^{16}$. Na série vítimas do racismo, ditadura militar, miséria social etc; no tempo presente o Estado brasileiro acrescenta o genocídio praticado no contexto da Covid-19.

15 Segundo a Rede de Observatórios da Segurança, quando comparados os dados de abril de 2019 com abril de 2020, no Estado do Rio de Janeiro mortes decorrentes de ação policial cresceram 57,9\%. Para o Estado de São Paulo, o Fórum Brasileiro de Segurança Pública indica no mesmo período um aumento de 53\% dos casos. Cf. CAAF/Unifesp. Determinação de suspensão das operações policiais em comunidades do Rio de Janeiro durante a pandemia. Boletim No 6, 2020.

16 São falas presidenciais proferidas no contexto pandemia no Brasil. A primeira em 20 de março de 2020, quando o país apresentava oficialmente 11 mortes: "Não vai ser uma gripezinha que vai me derrubar". A segunda em 28 de abril de 2020, quando o país contava com o cálculo governamental de 5.017 mortes: "E daí? lamento, quer que eu faça o quê?", Cf. DELLA; CHAID; URIBE (2020); CHAID; CARVALHO (2020). 
Em nosso território as mortes por Covid-19 não decorrem apenas do vírus. Também não são consequência de uma espécie de loucura suicida ou de uma ineficácia governamental. Como no massacre à Guerrilha do Araguaia, o genocídio em curso faz parte de uma política de Estado cujo um dos objetivos é fabricar mortes, que embora atinjam toda a comunidade política, incidem com mais intensidade sob grupos específicos.

Como no Araguaia, trata-se também de negar e mentir sobre essas mortes. Contudo, se com relação à Guerrilha o acontecimento foi recusado pelas Forças Armadas durante mais de duas décadas, se arquivos e restos mortais permanecem no status desaparecidos; o negacionismo que opera na Covid-19 surge atualizado. $\mathrm{O}$ aparelho de Estado reconhece mortes, enquanto desaparece com óbitos e registros através de baixas testagens, de subnotificações e de mudanças nas metodologias de contagem ${ }^{17}$.

Desse modo, enquanto o montante de vítimas (diário, somado, flutuante) adquire aparência de normalidade, o conjunto de lacunas e manipulações contribui com a produção de uma incerteza social, propiciando tanto o descuido da população para com sua vida e sua morte como o afrouxamento das medidas de isolamento social. Sem testes, sem Covid-19. Menos mortes, gripezinha. Mas como nem tudo é ausência e falsidade, instala-se uma guerra de narrativas, que implica na constituição de uma percepção social composta na mistura da mentira com os fatos. Enfim, embora as programadas falhas estatísticas não eliminem o real do fazer morrer, deixar morrer que atravessa a Covid-19 no país, o distorcem.

A distorção possibilita que os desassistidos de medidas garantidoras do fica em casa, assim como os corpos desprotegidos, já que destituídos de real acesso aos sistemas de higiene e proteção como água, álcool em gel e máscara, sejam jogados às zonas de contágio. Tornando-se então corpos matáveis, que matam e se matam, num país onde morre-se também de fome, eletrochoque, murro e bala. Enquanto isso sepultamentos tornam-se atípicos. Desaparecem os tradicionais rituais de despedida e luto. Sem velório, poucos familiares, sem familiares, sem corpos.

No caso dos indígenas as medidas de morte são ainda convenientes com os interesses de exploração de seus territórios. $O$ vírus penetra em suas aldeias e corpos operando como parte de uma política eugenista que atende aos interesses do capitalismo e seu desejo de limpeza dos obstáculos à devastação do que resta das florestas.

17 A ausência de testagens possibilita ainda o registro de mortes como se fossem decorrentes de causas associáveis à Covid-19, mas não do vírus (por exemplo, síndrome respiratória aguda grave). Com relação à distorção do número de vítimas através de subnotificações e de mudanças nas metodologias de contagem cf. CAAF/Unifesp. A distorção dos números. Boletim No 6 (2020); MARQUES (2020); ROSSI (2020). 
Com a Covid-19 os povos indígenas têm se constituído parte do coletivo das vítimas emblemáticas. Como indica o pesquisador Bruno Bernardi, a maioria das comunidades da Reserva de Dourados (MS) não apenas vive em pequenos espaços como sofre com a escassez de água. Somando-se ainda práticas de desumanização a que essas populações são historicamente submetidas e ao preconceito de raça e ao ódio, ampliados pelo estigma de possíveis transmissoras do vírus (2020). Entretanto, o governo central proíbe medidas que protegeriam etnias de diferentes territorialidades. Isso ocorreu em 2 de julho de 2020, quando o Presidente da República, com 16 vetos, sancionou a lei 14.019. Dentre as suspensões estão a garantia de acesso a uma série de itens fundamentais ao sobreviver ao vírus como água potável, cestas básicas, produtos de higiene e limpeza, leitos hospitalares e materiais informativos para os povos indígenas, os quilombolas e as populações tradicionais (ISA, 2020).

Quanto aos sepultamentos atípicos, para os povos originários a complexidade vai além dos caixões lacrados e dos velórios reduzidos. Para eles, é fundamental que os corpos de seus mortos retornem as suas aldeias e passem por rituais que variam de etnia para etnia. No caso dos Yanomami sepultamentos são inaceitáveis. Eles não enterram seus mortos, seus corpos são cremados e passam por celebrações que envolvem dimensões visíveis e invisíveis e onde as cinzas dos ossos do morto são parte essencial (KOPENAWA; ALBERT, 2019). Ocorre que no contexto da Covid-19, sem autorização ou comunicação aos familiares o Estado brasileiro tem enterrado corpos Yanomami.

Os corpos simplesmente desaparecem (BRASIL; COSTA, 2020). Mas como se o que ocorre com os Yanomami fosse ainda insuficiente, o aparelho de Estado institucionaliza possibilidades de outros desaparecimentos. Trata-se da Portaria Conjunta n. 2 de 28 de abril de 2020, firmada entre o Ministério da Saúde e o Conselho Nacional de Justiça, que abre exceções ao permitir que o sepultamento de pessoas não identificadas ocorra sem o usual registro civil de óbito. Embora a Portaria estabeleça a necropsia para casos de suspeita de morte violenta e para morte natural de pessoas que estavam sob a custódia do Estado, como a população carcerária. Embora crie formas de controle visando futuras localizações, essas informações poderão ser registradas sempre que possível'18.

Como sugerido anteriormente, trabalhamos com a hipótese de que embora fabricados em contextos distintos, as mortes e os desaparecimentos de corpos e registros associados à Covid-19 podem ser compreendidos como

18 É curioso observar que a expressão sempre que possível decorre da Lei 6.015/73, vigente no governo do presidente general Ernesto Geisel, quando a produção de vítimas políticas de desaparecimento forçado aumentou. Cf. DOSSIÊ Ditadura (2009). Sobre a Portaria Conjunta n. 2 como substituta da Portaria Conjunta n. 1, que legitimava até mesmo a cremação de corpos não identificados, cf. CAAF/Unifesp. Boletim CAAF/Unifesp de enfrentamento a Covid-19. N. 02 (2020). 
modernizações do modo como o aparelho de Estado produziu os desaparecimentos políticos da ditadura e seus vazios de memória. No contemporâneo emerge nova memória lacunar, ao mesmo tempo em que incertezas se tornam engrenagens potencializadoras de esquecimentos. Afinal é uma pandemia ou uma gripezinha? Quantos se contaminaram? Quantos morreram? Será que desapareceram? Onde enterraram os corpos? Morreram mesmo do vírus?

Ainda lembrando o Araguaia, talvez o aparelho de Estado pense que não basta matar, é preciso também torturar os familiares com dúvidas sobre a causa mortis e o que foi feito com os corpos de seus entes queridos. Fortalece-se a constituição dos lutos inconclusos, das subjetividades feridas, das memórias dolorosas e traumáticas. Potencializa-se ainda o vir à tona de ocultamentos propiciadores de impunidades.

Dito de outro modo, a composição desses vazios de memória pode ser vista como parte de um plano de desresponsabilização do Estado e de seus agentes. Um projeto que infiltra um reconhecimento dubio e de baixa intensidade com relação à letalidade do vírus e aos efeitos que a pandemia produz nos corpos e nas subjetividades diversamente afetados. Constrói-se assim um campo fértil à aceitabilidade da não responsabilização criminal dos produtores do incontável número de vítimas, ainda que como no Araguaia exista fortes indicações de que as ações e as omissões governamentais não apenas são intencionais como matam parcelas da população.

No caso dos indígenas, para a jurista Deisy Ventura, as ações e omissões que os afetam podem ser tipificadas como genocídio, o mais grave entre os crimes contra a humanidade ${ }^{19}$. "Genocídio não é só colocar pessoas num paredão (ou numa câmara de gás) e fuzilar as pessoas. O genocídio se dá também ao suprimir as condições necessárias à vida e às condições à saúde" (apud BRUM, 2020b, s/n) ${ }^{20}$.

Diz ainda Ventura, "processos são movidos visando a responsabilização de pessoas que atentam contra à vida da população vulnerável ou contra grupos específicos", mas também fazem "com que a verdade apareça na voz das vítimas ou de seus familiares". Para a jurista, como ocorre com relação à ditadu-

19 Estatuto de Roma do Tribunal Penal Internacional. Artigo 6. Crime de Genocídio. "Para os efeitos do presente Estatuto, entende-se por "genocídio", qualquer um dos atos que a seguir se enumeram, praticado com intenção de destruir, no todo ou em parte, um grupo nacional, étnico, racial ou religioso, enquanto tal: a) Homicídio de membros do grupo; b) Ofensas graves à integridade física ou mental de membros do grupo; c) Sujeição intencional do grupo a condições de vida com vista a provocar a sua destruição física, total ou parcial; d) Imposição de medidas destinadas a impedir nascimentos no seio do grupo; e) Transferência, à força, de crianças do grupo para outro grupo".

20 Vale lembrar que de dezembro de 2019 até julho de 2020 o presidente da República foi denunciado em três ocasiões por crime contra a humanidade ao Tribunal Internacional. Na última, por uma coalizão de 60 entidades majoritariamente da área da saúde. Cf. BEATRIZ (2020). 
ra, periodicamente teremos que provar as milhares de mortes da Covid-19. Essa "história terá que ser contada de forma incessante". E completa, "não há exagero em falar de crimes contra a humanidade com relação ao que está acontecendo hoje no Brasil referente à Covid-19" (apud BRUM, 2020b, s/n) ${ }^{21}$.

A conexão entre as manipulações dos dados da Covid-19 e os vazios que constituem as memórias da ditadura ajuda-nos ainda perceber que um país se define também pelas mortes, pelas memórias e pelos esquecimentos que fabrica. Se por um lado não há memória sem esquecimento, por outro, ao vivenciarmos nova tentativa do aparelho de Estado em edificar uma memória a partir do apagamento de seus rastros, é inevitável nos perguntarmos a quem interessa o controle da memória?

Indo à Belém de 1748-1750, lembramos que nesses tempos, a cidade viveu uma crise epidêmica com ao menos 16 mil vítimas indígenas (VIEIRA JUNIOR; MARTINS, 2015, p. 301). Dela falaram igreja, juízes, governadores da capitania do Grão-Pará, vereadores, proprietários de escravos indígenas, religiosos, conselheiros reais que viviam em Lisboa e até o rei português D. José I. Porém as vozes dos principais atingidos chegaram como lapsos de quem controla memórias. Os indígenas foram os mais afetados. Entretanto, suas falas não aparecem nos registros (VIEIRA JUNIOR, 2020).

Mas se as vozes dos atingidos não aparecem nos registros, se suas narrativas são inconfiáveis; fato que ocorre, por exemplo, com sobreviventes da repressão política ditatorial cujos relatos são ainda tratados como se pertencessem a um grupo de traumatizados, danificados e ressentidos. Afinal, quem detém a legitimidade sobre o vivido?

Apesar da complexidade e das lacunas que atravessam a produção das memórias acerca da ditadura e da Covid-19, com o antropólogo Bruce Albert afirmamos que "roubar os mortos alheios e negar o seu luto sempre foi o estágio supremo da barbárie, no desprezo e na negação do Outro (étnico e/ou político)" (apud BRUM, 2020a, s/n).

\section{Considerações finais}

Vivemos ainda um tempo de fazer morrer, deixar morrer. Um tempo de

21 É importante registrar ainda, o governo utiliza-se de um modo operacional que mesmo quando recua, tenta. Isso ocorreu, por exemplo, com a Portaria 419 da Fundação Nacional do Índio. De acordo com Ventura, ela se apresenta como medida "que vai coibir o contato com as comunidades isoladas. Só que, no meio, olhando com lupa, essa portaria abre uma exceção: a de que poderia haver o contato com as populações isoladas com autorização da Funai. O Governo tenta, sempre. A intenção é clara. Há então uma resposta muito forte da sociedade civil. Há uma recomendação do Ministério Público Federal, ainda em março, e então essa portaria é modificada. Mas a tentativa está lá" apud BRUM (2020b, s/n). 
militarismo, de destruição planetária, de ameaça de extinção do humano. Um tempo em que é cada vez mais indiscernível a separação entre o humano e os fluxos eletrônicos, (MBEMBE, 2017), mas também entre o humano e outras formas de vida (KOPENAWA; ALBERT, 2019).

Um tempo em que a democracia planetária e ao mesmo tempo local revela-nos que o contrato e a submissão dos súditos-cidadãos não promovem o prometido fim das guerras de todos contra todos. Ao contrário, as democracias contemporâneas acrescentam mais violência a violência. São modos de agir típicos do homem da mercadoria, que tem paixão desenfreada pela mercadoria. Homens que "ficaram muito satisfeitos consigo mesmos [...]. E assim as palavras das mercadorias e do dinheiro se espalharam por toda a terra de seus ancestrais" (KOPENAWA; ALBERT, 2019, p. 407). E são esses homens que realmente fabricam guerras de extermínio de todos contra todos.

Dito de outro modo, é o homem branco que faz a guerra do contra ao mesmo tempo em que transforma o sujeito de direito em mercadoria. Para Mbembe, "a cena mais dramática desta redução a pó é o linchamento. Este representa uma forma imensa, grotesca e exibicionista da crueldade racista que ocorre não atrás dos muros de uma prisão, mas no espaço público" $(2017$, p. 35).

Fazer morrer, deixar morrer corpos, mas também memórias. Negar modos de matar que ocorrem nas prisões e a céu aberto. Mortes que não acontecem apenas por meio de ataques secretos aos corpos e de torturas, mas também através de execuções sumárias e públicas, que chegam acompanhadas de incessantes tentativas de apagamentos de seus rastros.

No processo, gera-se uma insegurança permanente contra o Outro. De fato, nossa democracia securitária necessita desse estado de insegurança. A relação de inimizade é sua peça essencial. Se o inimigo é aquele a quem se pode fazer morrer, deixar morrer, se é ele que alimenta a insegurança, como na ditadura o inimigo está entre nós e seu extermínio ampara-se

[...] na lei da espada, é o antagonismo "em nome do qual se pode
pedir aos seres humanos para fazerem o sacrifício das suas vidas" (a
morte pelos outros), em nome do qual o Estado pode "dar a alguns o
poder de ferir e de matar outros homens" (dar a morte), pelo simples
fato de pertencerem real ou presumidamente ao campo do inimigo
[...] Mas não passa de um assunto de Estado e de morte delegada,
uma vez que nele está em causa não apenas a possibilidade do sacri-
fício e da dádiva de si, mas também, e literalmente, a possibilidade
do suicídio (MBEMBE, 2017, p. 82-83).

Mbembe (2017) nos diz ainda que "as linhas entre resistência e suicídio, sacrifício e redenção, martírio e liberdade, são difusas" (p. 153). Porém fala também que "são poucos os sofrimentos considerados injustos" (p. 66).

No Brasil, é fato, a morte de tantos segue como ferida aberta na memó- 
ria, que em geral se constituí acompanhada de permanentes impunidades. Em 2020 completamos trinta e cinco anos do final da ditadura militar (19641985); dez anos da sentença da Corte Interamericana de Direitos Humanos que condenou o Estado brasileiro no caso Araguaia (2010); vinte e oito anos do Massacre do Carandiru/SP, quando as forças de segurança estatais mataram ao menos 111 detentos (1992); vinte e quadro anos do Massacre de Eldorado dos Carajás, sudeste do Pará, quando 21 camponeses foram assassinados pela Polícia Militar, 19 morreram no local; vinte três anos da morte de Galdino Jesus dos Santos, da etnia Pataxó, queimado vivo num ponto de ônibus por cidadãos de Brasília (1997); quatorze anos dos Crimes de Maio de 2006, quando cerca de 600 jovens periféricos foram assassinados pela Polícia Militar de São Paulo; um ano do assassinato, por madeireiros, de Paulinho Guajajara (novembro de 2019); um ano da morte dos nove jovens de Paraisópolis (dezembro de 2019); um mês do linchamento de João Alberto por seguranças de uma das unidades da rede Carrefour, em Porto Alegre (novembro de 2020).

No país denominado Brasil, são múltiplos os corpos exterminados e afetados pelo fazer morrer, deixar morrer. E todas essas mortes e traumas estão marcados pelas mãos assassinas do aparelho de Estado e por suas estruturas de gestão, assim como por sua simpática omissão. A lista segue sendo atualizada. Até quando?

Finalizo retomando a guerra e a guerra entre memórias. Se o pensador camaronês Achille Mbembe nos diz que se houver guerra, deverá ser "contra tudo o que condena a grande maioria da humanidade à paragem prematura de respiração" (2020, s/n). Se Ailton Krenak indica que "durante um tempo, éramos nós, os povos indígenas, que estávamos ameaçados de ruptura ou da extinção dos sentidos de nossas vidas, hoje estamos todos na eminência de a Terra não suportar nossa demanda" (2019, p. 45). Se Davi Kopenawa fala aos indígenas: "devemos parar de guerrear entre nós e fixar nosso pensamento neles e na sua hostilidade contra nós" (KOPENAWA; ALBERT, 2019, p. 453).

Parafraseando Gilles Deleuze, em especial quando diz que o

[...] combate-contra procura destruir ou repelir uma força [...], mas o combate entre, ao contrário, trata de apossar-se de uma força para fazê-la sua. O combate entre é o processo pelo qual uma força se enriquece ao se apossar de outras forças somando-se a elas num novo conjunto, num devir (2011, p. 170).

Nas guerras contemporâneas talvez seja preciso destruirmos as tecnologias criadoras de memórias fortalecedoras da guerra do contra, fundamentalmente capitalistas, ocidentais e brancas. Rachar suas engrenagens por meio de um combate entre, em que as memórias minoritárias se enriquecem ao se apossarem e ao mesmo tempo transformarem as memórias do contra. 
Somando-se então a elas num novo conjunto, num devir múltiplo, logo menos branco, pois como faz ver Davi Kopenawa, "os brancos não sonham tão longe [...]. Dormem muito, mas só sonham consigo mesmos" (2019, p. 390).

\section{Referências}

AGAMBEN, Giorgio. Estado de exceção. Trad. Iraci D. Poleti. São Paulo: Boitempo, 2004.

ARENDT, Hannah. Origens do totalitarismo. Trad. Roberto Raposo. São Paulo: Companhia das Letras, 1989.

BAGULHÃO: a voz dos presos políticos. Comissão da Verdade Estadual de São Paulo Rubens Paiva. São Paulo: CVESP Rubens Paiva. 2014.

BEATRIZ, Jucá. Profissionais de saúde levam a Haia denúncia contra Bolsonaro por genocídio e crime contra a humanidade. El Pais, 26 jul. 2020, Disponível em: https://brasil.elpais.com/brasil/2020-07-26/profissionais-desaude-denunciam-bolsonaro-por-genocidio-e-crime-contra-a-humanidadeem-haia.html. Acesso em: 28 jul. 2020.

BERNARDI, Bruno. Covid-19 e os povos indígenas Kaiowá e Guarani no Mato Grosso do Sul. Boletim CAAF/Unifesp de enfrentamento da Covid-19. №. Especial. São Paulo, 29 mai. 2020.

BRASIL, Katia; COSTA, Emily. Ponte Jornalismo. 26 jun. 2020. Três corpos de bebês Yanomami estão em cemitério e um no IML de Boa Vista (RR). Disponível em: https://ponte.org/tres-corpos-de-bebes-yanomamiestao-em-cemiterio-e-um-no-iml-de-boa-vista-rr/?fbclid=IwAR1HM_ ftGnjorVICKmWnCc3UBROgDmr-_JQKfqzAt5_p5VDKId21iCMIJaE. Acesso em: 30 jun.2020.

BRUM, Eliane. Mães Yanomami imploram pelos corpos de seus bebês. El Pais, 24 jun. 2020a. Disponível em: https://brasil.elpais.com/brasil/2020-06-24/ maes-yanomami-imploram-pelos-corpos-de-seus-bebes.html. Acesso em: 27 jul. 2020.

BRUM, Eliane. Há indícios significativos para que autoridades brasileiras, entre elas o presidente, sejam investigadas por genocídio. El País, 22 jul. 2020b. Disponível em: https://brasil.elpais.com/brasil/2020-07-22/ 
ha-indicios-significativos-para-que-autoridades-brasileiras-entre-elas-opresidente-sejam-investigadas-por-genocidio.html. Acesso em: 27 jul. 2020. CAAF/Unifesp. Sobre a Portaria Conjunta n. 2, de 28 de abril de 2020 sepultamento de pessoas não reclamadas e não identificadas. Boletim CAAF/ Unifesp de enfrentamento da Covid-19. n. 2, São Paulo, s/d.

CAAF/Unifesp. Determinação de suspensão das operações policiais em comunidades do Rio de Janeiro durante a pandemia. Boletim CAAF/Unifesp de enfrentamento da Covid-19. n. 6, São Paulo, 11 jun. 2020.

CAAF/Unifesp. A distorção dos números. Boletim CAAF/Unifesp de enfrentamento da Covid-19, n. 6, São Paulo, 11 jun. 2020.

CAVASSA, Caroline; CESAR, Janaina. Documento inédito mostra que número de presos nos primeiros dias do golpe militar de 64 pode ser quatro vezes maior. The Intercept_Brasil, 30 mar. 2019. Disponível em: https://theintercept. com/2019/03/30/documento-inedito-mostra-que-numero-de-presos-nosprimeiros-dias-do-golpe-militar-de-64-pode-ser-quatro-vezes-maior/. Acesso em: 10 jul. 2019.

CHAID, Julia; CARVALHO, Daniel. "E daí? Lamento, quer que eu faça o quê?", diz Bolsonaro sobre recorde de mortos por coronavírus. Folha de São Paulo, 28 abr. 2020. Disponível em: https://www1.folha.uol.com.br/ equilibrioesaude/2020/04/e-dai-lamento-quer-que-eu-faca-o-que-dizbolsonaro-sobre-recorde-de-mortos-por-coronavirus.shtml. Acesso em: 10 mai. 2020.

CLASTRES, Pierre. Arqueologia da violência: pesquisas de antropologia política. Trad: Paulo Neves. São Paulo: Editora Cosac \& Naify, 2004.

COMISSÃO da Verdade do Estado de São Paulo/Rubens Paiva. São Paulo, Assembleia Legislativa do Estado de São Paulo, 2015. Disponível em: http:// comissaodaverdade.al.sp.gov.br/. Acesso em: 10 jan. 2021.

COMISSÃO de Anistia. Disponível em: http://justica.gov.br/seus-direitos/ anistia. Acesso em: 28 fev. 2018.

COMISSÃO Nacional da Verdade. Relatório da Comissão Nacional da Verdade.

Brasília, Casa Civil, 2014. Disponível em: http://www.cnv.gov.br/. Acesso em: 3 ago. 2017. 
CORTE INTERAMERICANA DE DIREITOS HUMANOS. Caso Lund e outros (Guerrilha do Araguaia) vs. Brasil: sentença de 24 de novembro de 2010. Disponível em: http:// www.corteidh.or.cr/docs/casos/articulos/seriec_219_por.pdf. Acesso em: 15 dez. 2018.

DANTAS, Dimitrius; CAETANO, Guilherme. Laudos apontam "asfixia mecânica" em Paraisópolis. Época, 2 dez. 2019. Disponível em: https://epoca.globo. com/brasil/laudos-do-iml-apontam-asfixia-mecanica-em-mortes-deparaisopolis-24113753. Acesso em: 16 jun. 2020.

DELEUZE, Gilles. Para dar fim ao juízo. In: Crítica e clínica. Trad. Peter Pál Pelbart. São Paulo: Editora 34, 2011.

DELEUZE, Gilles; GUATTARI, Félix. Capitalismo e esquizofrenia. Trad. Aurélio Guerra Netto; Ana Lúcia de Oliveira, Lúcia Cláudia Leão, Suely Rolnik. São Paulo: Editora 34, 2012.v. 3. (Coleção Mil Platôs).

DELLA, Ricardo; CHAID, Julia; URIBE, Gustavo. "Não vai ser uma gripezinha que vai me derrubar", diz Bolsonaro sobre coronavírus. Folha de São Paulo, 20 mar. 2020. Disponível em: https://www1.folha.uol.com.br/poder/2020/03/ nao-vai-ser-uma-gripezinha-que-vai-me-derrubar-diz-bolsonaro-sobrecoronavirus.shtml?origin=uol. Acesso em: 10 abr. 2020.

DIOGO, Adriano. A realidade da tortura não é uma disputa semântica. Diário do Centro do Mundo, 24 mai. 2020. Disponível em: https://www. diariodocentrodomundo.com.br/a-realidade-da-tortura-nao-e-uma-disputasemantica-por-adriano-diogo/. Acesso em: 16 jun. 2020.

DOSSIÊ Ditadura: mortos e desaparecidos políticos no Brasil (1964-1985). São Paulo: Imprensa Oficial do Estado de São Paulo: Instituto de Estudos sobre a Violência do Estado, 2009.

FOUCAULT, Michel. Vigiar e punir: nascimento da prisão. Trad. Raquel Ramalhete. Petrópolis: Vozes, 1999.

FOUCAULT, Michel. Em defesa da sociedade: Curso no Collège de France (1975-1976). Trad. Maria Ermantina Galvão. São Paulo: Martins Fontes, 2005.

FREUD, Sigmund. Luto e melancolia. In: Sigmund Freud: edição standard brasileira das obras psicológicas completas. Rio de Janeiro: Imago, 1996. v. 14. 
GUATTARI, Félix. Caosmose: um novo paradigma estético. Trad. Ana Lúcia de Oliveira, Lúcia Cláudia Leão. São Paulo: Editora 34, 2012.

GUATTARI, Félix; ROLNIK, Suely. Micropolítica: cartografias do desejo. Petrópolis: Vozes, 1996.

ISA. Veta os vetos, Alcolumbre. ISA, 8 jul. 2020. Disponível em: https://www. socioambiental.org/pt-br/blog/blog-do-isa/veta-os-vetos-alcolumbre. Acesso em: 10 jul. 2020.

KRENAK, Ailton. Ideias para adiar o fim do mundo. São Paulo: Companhia das Letras, 2019.

KOPENAWA, Davi; ALBERT, Bruce. A queda do céu: palavras de um xamã yanomami. Trad. Beatriz Perrone-Moisés. São Paulo: Companhia das Letras, 2019.

MARQUES, João Vitor. COVID-19: 'nova metodologia' do governo de MG faz ocupação de UTIs despencar. Estado de Minas Gerais, 6 jul. 2020. Disponível em: https://www.em.com.br/app/noticia/gerais/2020/07/06/interna_ gerais, 1163154/Covid-19-novo-metodo-do-governo-de-mg-faz-ocupacaode-utis-despencar.shtml. Acesso em: 9 jul. 2020.

MBEMBE, Achille. Políticas de Inimizade. Trad. Marta Lança. Lisboa: Antígona, 2017.

MBEMBE, Achille. Necropolítica. Trad. Renata Santini. São Paulo: $\mathrm{n}-1$ edições, 2018a.

MBEMBE, Achille. Crítica da Razão Negra. Trad. Sebastião Nascimento. São Paulo: $n$-1 edições, 2018b.

MBEMBE, Achille. O direito universal à respiração, 2020. Disponível em: http:// www.ihu.unisinos.br/78-noticias/598111-o-direito-universal-a-respiracaoartigo-de-achille-mbembe. Acesso em: 29 jul. 2020.

OLIVEIRA, Bárbara. "Morte por coronavírus é semelhante a afogamento", diz médico. A Gazeta, 20 mar. 2020. Disponível em: https://www.agazeta.com.br/ es/gv/morte-por-coronavirus-e-semelhante-a-afogamento-diz-medico-0320. Acesso em: 15 jun. 2020. 
QUEIROZ, Silvia Maria Brandão. As máquinas de memória: o corpo-vítima da ditadura militar brasileira como peça dos processos de subjetivação do contemporâneo. 2019. Tese (Doutorado em Filosofia) - Escola de Filosofia, Letras e Ciências Humanas. Universidade Federal de São Paulo, Campus Guarulhos, São Paulo, 2019.

ROSSI, Marina. Sem alarde, São Paulo muda divulgação de óbito da Covid-19 e especialistas criticam. El País. São Paulo, 23 jul. 2020. Disponível em:

STABILE, Artur. Corregedoria conclui que PMs agiram em "legítima defesa" no massacre de Paraisópolis. Ponte Jornalismo. 7 fev. 2020. Disponível em: https:// ponte.org/corregedoria-conclui-que-pms-agiram-em-legitima-defesa-nomassacre-de-paraisopolis/. Acesso em: 16 jun. 2020.

TELES, Janaina de Almeida. Memória dos cárceres da ditadura: os testemunhos e as lutas dos presos políticos no Brasil. 2011. Tese (doutorado) - Departamento de História da Faculdade de Filosofia, Letras e Ciências Humanas, Universidade de São Paulo, São Paulo, 2011.

UCHIANAKA, Fabiana. Viúva de guerrilheiro repudia busca feita pelo Exército e diz que segredo sobre arquivos da ditadura é "covardia". Uol, 8 jul. 2009. Disponível em: https://noticias.uol.com.br/politica/2009/07/08/ult5773u1631. jhtm. Acesso em: 10 out. 2020.

VECCHI, Roberto. O passado subtraído da desaparição forçada: Araguaia como palimpsesto. Estudos de Literatura Brasileira Contemporânea, Brasília, n. 43, jun., p.133-149, 2014.

VIEIRA JUNIOR, Antônio Otaviano. O direito de fala e de memória na epidemia. Boletim Ciências Sociais. n. 30. Publicado em 29 abr. 2020. Disponível em: http:// anpocs.org/index.php/publicacoes-sp-2056165036/boletim-cientistas-sociais/2344boletim-n-30-cientistas-sociais-e-o-coronavirus?idU=3. Acesso em: 5 mai. 2020.

VIEIRA JUNIOR, Antônio Otaviano; MARTINS, Roberta Savaia. Epidemia de sarampo e trabalho escravo no Grão-Pará 1748-1778. Revista Brasileira de Estudos de População, São Paulo, v. 32, n. 2, p. 293-311, 2015.

Recebido em: 27 de janeiro de 2021

Aprovado em: 27 de abril de 2021. 